\title{
A CAPACIDADE INSTITUCIONAL DO CONSELHO ADMINISTRATIVO DE RECURSOS FISCAIS - CARF PARA A DETERMINAÇÃO DE STANDARDS COMO SOLUÇÃO PARA QUESTÕES TÉCNICAS - UM POSSÍVEL PARADIGMA: A FIXAÇÃO DE UM PRAZO MÍNIMO PARA RESGATE DAS CONTRIBUIÇÕES DO EMPREGADOR EM PREVIDÊNCIA COMPLEMENTAR APORTADOS JUNTO ÀS ENTIDADES ABERTAS*
}

\author{
THE INSTITUTIONAL CAPACITY OF ADMINISTRATIVE COUNCIL OF TAX APPEALS - ACTA \\ TO DETERMINE STANDARDS AS A SOLUTION FOR TECHNICAL ISSUES - A POSSIBLE \\ PARADIGM: THE ESTABLISHMENT OF A MINIMUM TERM FOR THE WITHDRAWAL OF \\ THE PENSION FUND
}

Julio Cesar Vieira Gomes**

\begin{abstract}
Resumo: O presente artigo examina a incidência de contribuições previdenciárias sobre a previdência complementar privada. Reconhece que a desvinculação da remuneração pelo artigo 202, §2 $2^{\circ}$ da Constituição Federal conferiu imunidade tributária ao benefício, orientando assim a solução hermenêutica para o conflito aparente entre as normas no artigo 28 , $\S 9^{\circ}$ alínea $p$ da Lei $n^{\circ} 8.212$, de 24/07/91.
\end{abstract}

Palavras-Chave: Contribuição previdenciária; Previdência complementar privada; Imunidade.

\begin{abstract}
This article examines the incidence of social security contributions on private supplementary pension. They are approached from the more general aspects, which covers the historical and legislative evolution on the subject, until the tax treatment in the practical and specifics cases that have been judged in the Administrative Council of Tax Appeals - CARF. Recognizes that the decoupling of remuneration by article 202, paragraph 2 of the Federal Constitution, introduced by 20th Amendment, dated 12/15/98, conferred tax immunity on the benefit, thus guiding the hermeneutic solution to the apparent conflict between the norms in the article 28, paragraph 9 p of Law No. 8.212 of July 24, 1991, included by Law No. 9.528, dated December 10, 1997, article 458, paragraph 2 of the Labor Protection Law, included by Law No. 10.243, of 19/06/2001 and articles 68 and 69, paragraph 1 of Complementary Law No. 109, dated 05/29/2001. In its more specific approach, it examines the possibility of setting a minimum period for the withdrawal of the contributions made by the employer as supplementary pension offered by private insurance companies.
\end{abstract}

Keywords: Social security tax; Pension fund; Tax immunity.

\section{INTRODUÇÃO}

Este artigo se propõe a examinar o tratamento tributário à previdência complementar privada oferecida pelas empresas a seus empregados e diretores. Durante mais de uma década a administração tributária tem se deparado com controvérsias tanto na escolha do dispositivo legal a

\footnotetext{
*Artigo submetido em 06 ago. 2018 e aceito para publicação em 05 out. 2018. Publicado em 19.12.2018.

${ }^{* *}$ Auditor-Fiscal da Receita Federal do Brasil, Doutorando em Direito pela Universidade do Estado do Rio de Janeiro, Rio de Janeiro, Rio de Janeiro, Brasil. $\square$ julio2612@gmail.com
} 
ser aplicado quanto à interpretação da norma nos hardcases tributários. Portanto, antes mesmo de enfrentar os casos mais difíceis as divergências já começam com a escolha de uma solução para o conflito aparente de normas aplicáveis às contribuições previdenciárias sobre previdência complementar privada.

No âmbito do Conselho Administrativo de Recursos Fiscais - CARF a jurisprudência tem se consolidado pela prevalência dos artigos 68 e 69, § $1^{\circ}$ da Lei Complementar ${ }^{\circ} 109$, de 29/05/2001 sobre o artigo $28, \S 9^{\circ}$ alínea $p$ da Lei ${ }^{\circ}$ 8.212, de 24/07/91, incluído pela Lei ${ }^{\circ}$ 9.528, de 10/12/1997, e sobre o artigo $458, \S 2^{\circ}$ da CLT, incluído pela Lei $n^{\circ} 10.243$, de 19/06/2001.

Mas ainda que se considere superada a divergência quanto a norma aplicável à previdência complementar privada oferecida pelas empresas a seus empregados e diretores, ficam pendentes de solução casos relacionados às características especiais dos programas oferecidos pelas empresas: decurso de tempo entre o aporte de valores e o resgate realizado pelos empregados ou diretores beneficiários e, tratando-se de entidade fechada, as restrições de acesso ao benefício em razão de algumas características da relação de emprego, como a faixa salarial e a condição de trabalhador temporário.

No exame desses hardcases tributários também abordaremos aspectos relacionados à capacidade institucional do Conselho Administrativo de Recursos Fiscais - CARF na construção de standards, o que oferece ganhos em eficiência pelo fato de ser um órgão eminentemente técnico e também em transparência e previsibilidade, o que se alinha com a necessária segurança jurídica e confiança legítima dos contribuintes.

Essa necessidade de solução através de standards deve ser cingida aos casos em que as opções, a despeito da razoabilidade dos fundamentos adotados, seja de um ou de outro lado, são excessivamente generalistas, excludentes entre si e de pouca precisão, o que coloca o julgador numa posição marcada pela incerteza ou, no mínimo, sem apoio em bases razoavelmente confiáveis. O caso especial que examinaremos é a discussão sobre a validade de um programa de previdência complementar privada patrocinado por entidade aberta que possibilite o resgate a qualquer tempo dos aportes realizados pela empresa. Entre as duas opções extremas, a completa liberdade de fixação de qualquer prazo para resgate (de 1 dias a décadas de participação no programa) e a restrição aos casos em que ocorre o desligamento do segurado da empresa pela aposentadoria ou óbito, parece-me válida a fixação pela administração tributária de um standard mais razoável e preciso que ofereça uma solução confiável e segura ao contribuinte. Como instância para a fixação de uma solução pacificadora, sem a qual a necessária segurança e previsibilidade desejada pelo contribuinte não poderá sem alcançada, coloca o CARF no centro dessa responsabilidade. Dentre os atores igualmente legitimados, o órgão administrativo especializado disporá de melhor capacidade institucional que os 
tribunais quando a melhor solução seja muito menos uma questão de hermenêutica, mas sim a adoção de critérios objetivos, os standards que delimitam o campo de validade no exercício da liberdade dos contribuintes.

Nossa abordagem está organizada em três partes: na primeira são apresentados os aspectos gerais; na segunda, tratamos da solução adotada pela Câmara Superior de Recursos Fiscais do CARF para o conflito aparente das possíveis normas aplicáveis e, por fim, examinaremos o hardcase de aplicação da Lei Complementar $n^{\circ} 109$, de 29/05/2001 quando o plano de benefícios contratado das entidades abertas possibilita resgates a curtíssimo prazo, o que tem sido objeto de autuações fiscais.

\section{EVOLUÇÃO HISTÓRICA E LEGISLATIVA DA PREVIDÊNCIA COMPLEMENTAR PRIVADA}

Embora nos anos 40 já tivéssemos iniciativas como a do Banco do Brasil para a complementação da aposentadoria de seus empregados, a primeira regulação da previdência complementar no Brasil surgiu com a Lei no 6.435, de 15/07/1977. Nela já havia a separação de suas disposições entre as entidades abertas e as fechadas:

Art. $4^{\circ}$ Para os efeitos da presente Lei, as entidades de previdência privada são classificadas: I - de acordo com a relação entre a entidade e os participantes dos planos de benefícios, em: a) fechadas, quando acessíveis exclusivamente aos empregados de uma só empresa ou de um grupo de empresas, as quais, para os efeitos desta Lei, serão denominadas patrocinadoras; b) abertas, as demais.

Para as entidades abertas, pode-se dizer que desde as primeiras disposições legais sobre seguro privado no Brasil já havia a possibilidade de as companhias seguradoras oferecerem capitalização sobre aportes com finalidade de oferecer ao interessado uma aposentadoria com rendas mensais complementares à paga pela previdência social; entretanto, a Superintendência de Seguros Privados - SUSEP, órgão controlador e fiscalizador da constituição e funcionamento das sociedades seguradoras e entidades abertas de previdência privada, considera que o marco da previdência privada tenha sido a criação em 10/01/1835 do MONGERAL - Montepio Geral de Economia dos Servidores do Estado ${ }^{1}$.

\footnotetext{
1 "O século XIX também foi marcado pelo surgimento da "previdência privada" brasileira, pode-se dizer que inaugurada em 10 de janeiro de 1835, com a criação do MONGERAL - Montepio Geral de Economia dos Servidores do Estado proposto pelo então Ministro da Justiça, Barão de Sepetiba, que, pela primeira vez, oferecia planos com características de facultatividade e mutualismo. A Previdência Social só viria a ser instituída através da Lei $n^{\circ} 4.682$ (Lei Elói Chaves), de 24/01/1923". Superintendência de Seguros Privados - SUSEP. Disponível em: http://www.susep.gov.br/menu/asusep/historia-do-seguro/. Acesso em: 17 set. 2017.
} 
Contudo, independentemente da discussão sobre seu marco histórico no Brasil, com a instituição do Sistema Nacional de Seguros Privados criado pelo Decreto-lei no 73, de 21/11/1977, o Conselho Nacional de Seguros Privados - CNSP e a SUSEP passariam a regular a previdência privada oferecida pelas entidades abertas de uma forma mais consistente e sistematizada.

Como vimos, a existência de disposições legais sobre previdência privada, principalmente das entidades abertas, remete a muitas décadas atrás, mas realmente o primeiro estatuto sobre essa atividade somente surgiu com a Lei $\mathrm{n}^{\mathrm{o}}$ 6.435, de 15/07/1977. Quando oferecida pelas entidades abertas, a competência foi mantida no Sistema Nacional de Seguros Privados, mas para as entidades patrocinadoras fechadas a competência seria reservada ao Ministério da Previdência e Assistência Social, atualmente, exercida pela Superintendência Nacional de Previdência Complementar PREVIC, autarquia de natureza especial vinculada ao Ministério da Fazenda:

Art. $7^{\circ}$ As entidades abertas integram-se no Sistema Nacional de Seguros Privados.

Art. 34. As entidades fechadas consideram-se complementares do sistema oficial de previdência e assistência social, enquadrando-se suas atividades na área de competência do Ministério da Previdência e Assistência Social.

Apesar de sua relevância para a escolha dos planos de benefícios a serem instituídos, a Lei $\mathrm{n}^{\circ}$ 6.435, de 15/07/1977 se omitiu quanto a diferenciação das modalidades “Benefício Definido BD” e “Contribuição Definida - CD”, conceitos trazidos pela experiência norte-americana do ERISA (Employee Retirement Income Security Act), aprovado em 02/09/1974. Somente em 2001 vieram a ser adotado com a Lei Complementar $n^{\circ} 109$, de 29/05/2001:

Art. $7^{\circ}(\ldots)$

Parágrafo único. O órgão regulador e fiscalizador normatizará planos de benefícios nas modalidades de benefício definido, contribuição definida e contribuição variável, bem como outras formas de planos de benefícios que reflitam a evolução técnica e possibilitem flexibilidade ao regime de previdência complementar.

E a constitucionalização da matéria surge com a Emenda Constitucional $n^{\circ} 20$, de 15/12/98 que ao deslocar o texto anterior para o artigo 201 reservou ao artigo 202 apenas a previdência privada. Além de trazer as características gerais do regime, também cuidou de desvincular da remuneração tanto os aportes em previdência privada quanto o resgate dos benefícios:

Art. 202. O regime de previdência privada, de caráter complementar e organizado de forma autônoma em relação ao regime geral de previdência social, será facultativo, baseado na constituição de reservas que garantam o benefício contratado, e regulado por lei complementar.

$\S 1^{\circ}$ A lei complementar de que trata este artigo assegurará ao participante de planos de benefícios de entidades de previdência privada o pleno acesso às informações relativas à gestão de seus respectivos planos.

$\S 2^{\circ}$ As contribuições do empregador, os benefícios e as condições contratuais previstas nos estatutos, regulamentos e planos de benefícios das entidades de previdência privada 
não integram o contrato de trabalho dos participantes, assim como, à exceção dos benefícios concedidos, não integram a remuneração dos participantes, nos termos da lei. (Redação dada pela Emenda Constitucional nº 20, de 1998).

\section{A TRIBUTAÇÃO DA PREVIDÊNCIA COMPLEMENTAR}

Como ponto de partida as regras constitucionais, o artigo 202, §2 desvincula da remuneração, principal base de cálculo das contribuições previdenciárias, os aportes realizados pelo empregador e reserva à lei as condições para exercício dessa imunidade.

Quanto as disposições em geral sobre previdência privada, o caput do mesmo artigo 202 exigiu, por sua vez, que a matéria fosse regulamentada por lei complementar. E até a edição do novo estatuto, permaneceria vigente a Lei $n^{\circ} 6.435$, de 15/07/1977.

Como haveria necessidade de lei complementar para as disposições mais atuais sobre previdência privada, instituto que vinha a cada ano ganhando maiores proporções, entendeu o legislador por bem reunir no mesmo estatuto todas as disposições, inclusive o tratamento tributário, embora as condições para exercício da imunidade também pudessem ser veiculadas por lei ordinária. Esse é um aspecto importante porque no que se refere às contribuições previdenciárias vigia a lei ordinária $\mathrm{n}^{\circ} 8.212$, de 24/07/91 e, assim, mesmo com a edição da Lei Complementar $\mathrm{n}^{\circ} 109$, de 29/05/2001 que regulou o artigo 202 da Constituição Federal e revogou a Lei n 6.435, de 15/07/1977 persiste a discussão sobre qual das leis deve prevalecer em relação ao tributo.

Ainda que se admita aqui o conflito aparente de normas jurídicas, o artigo $28, \S 9^{\circ}$, alínea $p$, parte final, da Lei $\mathrm{n}^{\circ}$ 8.212, de 24/07/91, incluído pela Lei $\mathrm{n}^{\circ}$ 9.528, de 10/12/1997, não deve prevalecer sobre os artigos 68 e 69, $\S 1^{\circ}$ da Lei Complementar $n^{\circ} 109$, de 29/05/2001, que passaram a regular a imunidade conferida pelo artigo $202, \S 2^{\circ}$ da Constituição Federal, pois além de melhor atender ao critério da especialidade, a LC $n^{\circ} 109$, de 29/05/2001 é posterior à Lei $n^{\circ} 8.212$, de 24/07/91:

Lei ${ }^{\circ}$ 8.212, de 24/07/91

Art. $28(\ldots)$

$\S 9^{\circ}(\ldots)$

p) o valor das contribuições efetivamente pago pela pessoa jurídica relativo a programa de previdência complementar, aberto ou fechado, desde que disponível à totalidade de seus empregados e dirigentes, observados, no que couber, os arts. $9^{\circ}$ e 468 da CLT; (Incluído pela Lei $\mathrm{n}^{\circ}$ 9.528, de 10.12.97)

Lei Complementar $n^{\circ} 109$, de 29/05/2001

Art. 68. As contribuições do empregador, os benefícios e as condições contratuais previstos nos estatutos, regulamentos e planos de benefícios das entidades de previdência complementar não integram o contrato de trabalho dos participantes, assim como, à exceção dos benefícios concedidos, não integram a remuneração dos participantes.

Art. 69. As contribuições vertidas para as entidades de previdência complementar, destinadas ao custeio dos planos de benefícios de natureza previdenciária, são dedutíveis para fins de incidência de imposto sobre a renda, nos limites e nas condições fixadas em lei. 
$\S 1^{\underline{0}}$ Sobre as contribuições de que trata o caput não incidem tributação e contribuições de qualquer natureza.

Em uma comparação entre os dispositivos legais, o artigo 28, $\S 9^{\circ}$, alínea p, parte final, da Lei $n^{\circ} 8.212$, de 24/07/91 exige para a não incidência da contribuição previdenciária que a previdência complementar seja disponibilizada à totalidade dos empregados e dirigentes da empresa; enquanto a LC $n^{\circ} 109 / 2001$ confere tratamento tributário diferente caso se trate de entidades abertas. As duas modalidades foram separadas em duas seções. Quando oferecidos por entidades fechadas, os planos de benefícios devem ser oferecidos a todos os empregados dos patrocinadores ou associados dos instituidores, reproduzindo-se, assim, texto semelhante a Lei n ${ }^{\circ} 8.212$, de 24/07/91, artigo 16, mas na seção que dispõe sobre os planos de benefícios de entidades abertas não há esse requisito. Conforme artigo 26, $\S \S 2^{\circ}$ e $3^{\circ}$, a empresa pode oferecê-lo apenas a grupos de categorias específicas de empregados:

Art. $28(\ldots)$

$\S 9^{\circ}$ Não integram o salário-de-contribuição para os fins desta Lei, exclusivamente:

p) o valor das contribuições efetivamente pago pela pessoa jurídica relativo a programa de previdência complementar, aberto ou fechado, desde que disponível à totalidade de seus empregados e dirigentes, observados, no que couber, os arts. $9^{\circ}$ e 468 da CLT; (Incluído pela Lei $\mathrm{n}^{\circ}$ 9.528, de 10.12.97).

Lei Complementar $n^{\circ}$ 109, de 29 de Maio de 2001

Art. 1 o $\mathrm{O}$ regime de previdência privada, de caráter complementar e organizado de forma autônoma em relação ao regime geral de previdência social, é facultativo, baseado na constituição de reservas que garantam o benefício, nos termos do caput do art. 202 da Constituição Federal, observado o disposto nesta Lei Complementar.

Art. $4^{\circ}$ As entidades de previdência complementar são classificadas em fechadas e abertas, conforme definido nesta Lei Complementar.

Seção II

Dos Planos de Benefícios de Entidades Fechadas

Art. 16. Os planos de benefícios devem ser, obrigatoriamente, oferecidos a todos os empregados dos patrocinadores ou associados dos instituidores.

$\S 1$ 1o Para os efeitos desta Lei Complementar, são equiparáveis aos empregados e associados a que se refere o caput os gerentes, diretores, conselheiros ocupantes de cargo eletivo e outros dirigentes de patrocinadores e instituidores.

\section{Seção III}

Dos Planos de Benefícios de Entidades Abertas

Art. 26. Os planos de benefícios instituídos por entidades abertas poderão ser:

I - individuais, quando acessíveis a quaisquer pessoas físicas; ou

II - coletivos, quando tenham por objetivo garantir benefícios previdenciários a pessoas físicas vinculadas, direta ou indiretamente, a uma pessoa jurídica contratante.

$\S 1^{\circ} \mathrm{O}$ plano coletivo poderá ser contratado por uma ou várias pessoas jurídicas.

$\S 2$ o O vínculo indireto de que trata o inciso II deste artigo refere-se aos casos em que uma entidade representativa de pessoas jurídicas contrate plano previdenciário coletivo para grupos de pessoas físicas vinculadas a suas filiadas.

$\S 3^{\circ}$ Os grupos de pessoas de que trata o parágrafo anterior poderão ser constituídos por uma ou mais categorias específicas de empregados de um mesmo empregador, podendo abranger empresas coligadas, controladas ou subsidiárias, e por membros de associações legalmente constituídas, de caráter profissional ou classista, e seus cônjuges ou companheiros e dependentes econômicos. 
§ 4ํㅜ Para efeito do disposto no parágrafo anterior, são equiparáveis aos empregados e associados os diretores, conselheiros ocupantes de cargos eletivos e outros dirigentes ou gerentes da pessoa jurídica contratante.

Portanto, um suposto programa de previdência complementar em regime fechado não oferecido à totalidade dos empregados não pode ser considerado como tal e as contribuições vertidas devem ser tributadas normalmente, eis que carecem de característica essencial de sua existência. As entidades fechadas são instituídas para o conjunto de empregados da patrocinadora e não para grupos de categorias específicas de empregados de um mesmo empregador, faculdade somente possível quando a opção é pelo regime aberto, conforme artigo $26, \S^{\circ}$ da lei.

Com efeito, nos programas das entidades fechadas somente os empregados da empresa têm acesso aos planos de benefício, sendo inacessíveis a terceiros. Também seria razoável, da mesma forma, concluir-se pela necessidade de ser disponível a todos os empregados.

Já para o regime aberto, adquirido das instituições financeiras em benefício de empregados, a lei faculta que a empresa contrate em benefício de grupos específicos de categorias de empregados plano de previdência complementar, artigo $26, \S 2^{\circ}$ e $3^{\circ}$ da lei. Então, neste caso não incidem contribuições previdenciárias ainda que o benefício não seja oferecido à totalidade dos empregados; porém, no caso dos programas em regime aberto, embora não seja necessário estendêlo à totalidade dos empregados e dirigentes, os grupos selecionados são de categorias de empregados, sem discriminações dentro de um mesmo grupo. A escolha recai sobre determinada categoria não como incentivo à produtividade ou a outras finalidades relacionadas ao trabalho, mas em razão de necessidades específicas. Do contrário, sendo possível uma negociação dentro do contrato individual de trabalho em que a previdência complementar seja oferecida ao empregado como uma contraprestação haveria uma caracterização como salário de contribuição, tal como definido no artigo 28 da Lei ${ }^{\circ} 8.212$, de 24/07/91.

Portanto, cumpridos os requisitos previstos na LC n ${ }^{\circ} 109$, de 29/05/2001 que os diferenciou conforme sejam os planos de benefícios oferecidos por entidades fechadas ou abertas, as contribuições previdenciárias não incidem sobre os aportes realizados pelas empresas em benefício de seus empregados e dirigentes:

\section{CAPÍTULO VIII DISPOSIÇÕES GERAIS}

Art. 68. As contribuições do empregador, os benefícios e as condições contratuais previstos nos estatutos, regulamentos e planos de benefícios das entidades de previdência complementar não integram o contrato de trabalho dos participantes, assim como, à exceção dos benefícios concedidos, não integram a remuneração dos participantes.

Art. 69. As contribuições vertidas para as entidades de previdência complementar, destinadas ao custeio dos planos de benefícios de natureza previdenciária, são dedutíveis para fins de incidência de imposto sobre a renda, nos limites e nas condições fixadas em lei. 
$\S 1^{\circ}$ Sobre as contribuições de que trata o caput não incidem tributação e contribuições de qualquer natureza.

$\S 2^{\mathrm{o}}$ Sobre a portabilidade de recursos de reservas técnicas, fundos e provisões entre planos de benefícios de entidades de previdência complementar, titulados pelo mesmo participante, não incidem tributação e contribuições de qualquer natureza.

Outro possível conflito de normas também poderia envolver o artigo 458, §2 $2^{\circ}$ da CLT. Com a redação da Lei $n^{\circ} 10.243$, de 19/06/2001, para os efeitos da relação de emprego não são considerados salários: vestuários, educação, transporte, assistência médica, seguros de vida e de acidentes pessoais, previdência privada e vale-cultura:

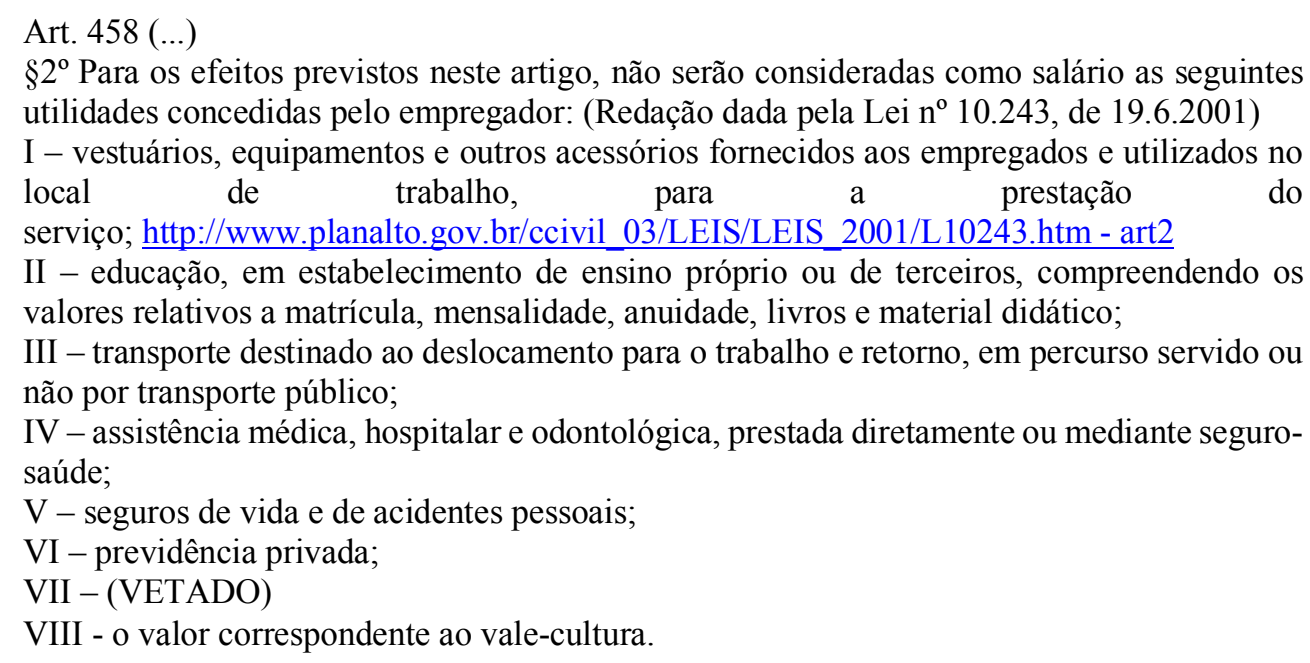

Contudo, para que não seja considerado parte dos salários é necessário que o plano de benefícios oferecido pela empresa e por ela considerado como previdência complementar apresente todas as características delineadas com obrigatórias pela LC $\mathrm{n}^{\circ} 109$, de 29/05/2001 a fim de que, efetivamente, possa como tal ser conceituado. Assim, penso que a melhor interpretação como solução harmônica do conflito aparente com o artigo 458, $\S 2^{\circ}$ inciso VI da CLT é afastar a previdência privada do conceito de salário somente quando revestida das características elementares do benefício, dentre as quais a disponibilidade a todos os empregados, quando por entidade fechada, e a possibilidade de concessão a grupos de empregados para a previdência complementar contratada das entidades abertas.

E quando pesquisamos a jurisprudência de nossos tribunais superiores quanto a incidência da contribuição previdenciária sobre as mesmas parcelas excluídas do salário pelo artigo $458, \S 2^{\circ}$ da CLT, não constatamos qualquer indicação da legislação trabalhista nos fundamentos adotados para afastá-las do campo de incidência. Nos casos em que se decidiu pela não incidência, o entendimento se apoiou na ausência de incremento patrimonial ao empregado, aproximando essas parcelas para a natureza indenizatória. Importante é a constatação de que nossos tribunais têm feito uma separação rígida entre as leis com finalidades distintas. Com efeito, a legislação trabalhista é cingida ao exame e aplicação aos casos sob competência da justiça do trabalho, sem referência para fins tributários. Foi 
assim no julgamento do RE 478.410/SP (auxílio-transporte), REsp 660.202/CE, REsp 441.096/RS e REsp 839.153/SC (seguro de vida em grupo) e REsp 1.185.685 (auxílio-alimentação).

A solução que adotamos já vinha sendo acolhida desde 2009 por uma das turmas ordinárias do CARF, com divergência das demais turmas competentes para apreciação dos recursos voluntários em matéria de contribuições previdenciárias:

Primeira turma ordinária da terceira câmara da segunda seção:

Acórdão nº 2301-00.571, em 20/08/2009:

“a partir da $\mathrm{LC} \mathrm{n}^{\circ}$ 109/2001, somente no regime fechado, a empresa deverá oferecer o benefício à totalidade dos segurados empregados, diretores, conselheiros ocupantes de cargo eletivo e outros dirigentes de patrocinadores e instituidores. Caso adotado o regime aberto, poderá oferecer o benefício a grupos de empregados ou dirigentes pertencentes a determinada categoria, mas não como instrumento de incentivo ao trabalho, eis que flagrantemente o caracterizaria como um prêmio e, portanto, gratificação".

Também nesse sentido o acórdão ${ }^{\circ}$ 2301-01.290, de 23/03/2010 (relator: Conselheiro Leonardo Henrique Pires Lopes). E transcorridos cinco anos desde o primeiro caso paradigmático, a tese aqui sustentada e defendida pela primeira turma ordinária da terceira câmara foi acolhida pela Câmara Superior de Recursos Fiscais do CARF - CSRF através do acórdão nº 9202-003.193, de 07/05/2014. Quando submetida a divergência a novo julgamento, a CSRF reafirmou neste ano a nossa tese pela prevalência da LC n 109/2001 (acórdãos $n^{\circ}$ 9202-005.241, de 14/03/2017 e $n^{\circ} 9202$ 005.317, de 18/04/2017).

\section{UM HARDCASE DA TRIBUTAÇÃO: AUTUAÇÕES FISCAIS FUNDAMENTADAS NO CURTO LAPSO TEMPORAL ENTRE APORTES E RESGATES}

A solução para o conflito em abstrato de regras tributárias, com a prevalência da $\mathrm{LC} \mathrm{n}^{\circ}$ 109, de 29/05/2001 sobre o artigo 28, $\S 9^{\circ}$, alínea “p”, parte final, da Lei n 8.212, de 24/07/91 e o artigo 458, $\S 2^{\circ}$ inciso VI da CLT, é somente uma fase preliminar para as divergências sobre a previdência complementar privada. A fase de aplicação da norma demanda uma busca de solução ainda mais complexa. Em muitos casos não será com a mera subsunção à LC n 109/2001 que o problema estará resolvido.

O hardcase que examinaremos está relacionado com o elemento temporal dos planos de previdência complementar privada, o lapso entre os aportes de valores junto às entidades abertas e o resgate realizado pelos empregados ou diretores beneficiários. De fato, não há dispositivo legal explícito que determine um decurso mínimo de tempo para que os empregados possam resgatar seus benefícios, nem mesmo pelas normas reguladoras da Superintendência de Seguros Privados - SUSEP, 
órgão regulador e fiscalizador da constituição e funcionamento das sociedades seguradoras e entidades abertas de previdência privada.

Essa característica é relevante porque acaba abrindo a possibilidade de um planejamento tributário onde as parcelas remuneratórias ordinárias sujeitas à incidência das contribuições previdenciárias sejam transportadas para os planos de previdência complementar privada, protegidas sob o manto da imunidade. Quanto menor o número de aportes mensais e o prazo mínimo para os resgates maior as chances de se desvirtuar a finalidade buscada pelo constituinte em incentivar a complementação da aposentadoria paga pelo regime geral de previdência social - RGPS.

A questão aqui é mais uma daquelas que ocupam as principais discussões quanto ao planejamento tributário abusivo. Para aqueles que acolhem o positivismo formalista defendido por Alberto Xavier (XAVIER, 2001. p. 19), na ausência de um limite temporal para os resgates dos aportes, o contribuinte teria a plena liberdade de fixá-lo como bem lhe convier, vedada ao intérprete e aplicador da lei qualquer valoração sobre os fatos, ainda que a ausência de um lapso temporal razoável tenha como única finalidade afastar a incidência tributária: “o princípio da determinação ou da tipicidade fechada [...] exige que os elementos integrantes do tipo sejam de tal modo precisos e determinados na sua formulação legal que o órgão de aplicação do direito não possa introduzir critérios subjetivos de apreciação na sua aplicação concreta".

Em sentido contrário, entre as duas soluções extremas, a completa liberdade de fixação de qualquer prazo para resgate (de 1 dias a décadas de participação no programa), de um lado, e a restrição aos casos em que ocorre o desligamento do segurado da empresa pela aposentadoria ou óbito, de outro, parece-me válida a fixação pela administração tributária de um standard mais razoável e preciso que ofereça uma solução confiável e segura ao contribuinte.

E ainda que muitas das características de seu desenho mereçam ser aperfeiçoadas, é o Conselho Administrativo de Recursos Fiscais - CARF que apresenta a melhor capacidade institucional para oferecer soluções razoáveis e precisas com ganhos em eficiência e segurança jurídica.

Essa necessidade de solução através de standards deve ser cingida aos casos em que as opções, a despeito da razoabilidade dos fundamentos adotados, seja de um ou de outro lado, são excessivamente generalistas, excludentes entre si e de pouca precisão, o que coloca o julgador numa posição marcada pela incerteza ou, no mínimo, sem apoio em bases razoavelmente confiáveis.

Com efeito, a função reguladora que naturalmente decorre da jurisprudência exercida pelos órgãos técnico-administrativos legitima o CARF como instância para a fixação de uma solução pacificadora, sem a qual a necessária previsibilidade desejada pelo contribuinte não poderá sem alcançada. Dentre outros atores igualmente legitimados, o órgão administrativo especializado disporá 
de melhor capacidade institucional que os tribunais quando a melhor solução seja menos uma questão hermenêutica e mais o esforço na fixação de critérios objetivos, formando standards de comportamento que delimitem a fronteira entre a validade no exercício da liberdade dos contribuintes e o planejamento abusivo.

Uma vez abandonados os dois extremos, ou seja, a suposta irrefutável e absoluta liberdade de fixação de qualquer prazo para resgate, mesmo que seja já a partir do dia seguinte ao aporte de valores na previdência complementar privada do empregado, e a imposição de que os resgates somente sejam possíveis quando da ocorrência dos eventos previstos pela previdência social (aposentadoria por tempo de contribuição ou idade, pensão por morte etc), a questão passa a ser de escolha de um prazo que possa ser considerado razoável, seguro e em conformidade com o instituto constitucional da previdência complementar privada oferecido pelas entidades abertas.

Adotando que a escolha de qualquer dos extremos não seja razoável e que o contribuinte tenha cumprido os demais requisitos da $\mathrm{LC}^{\circ}$ 109/2001, recaindo o problema apenas no fato de que a fiscalização tenha entendido que os resgates ocorreram em curto lapso de tempo dos aportes, não me parece que o tribunal seja a instituição mais adequada para determinar do prazo mínimo aceitável. Assim, concordamos com o diagnóstico do Prof. Sérgio André (ROCHA, 2017. p. 56): “o juiz médio não foi treinado e preparado, desde os bancos da graduação na Faculdade de Direito, para apreciar questões tributárias que fujam aos debates envolvendo princípios constitucionais e outras matérias de natureza essencialmente jurídica, normalmente radicadas na interpretação da Constituição Federal ou do Código Tributário Nacional. Nada obstante, sabe-se que a tributação vai muito além de tais tópicos, principalmente quando não se está discutindo teses jurídicas em ações ativas iniciadas pelos contribuintes, mas sim autos de infração lavrados considerando matérias concretas e a legislação especial de cada tributo. Este cenário impulsiona a importância adquirida por órgãos de julgamento como o CARF. Tornou-se lugar comum o reconhecimento de que no Conselho, independentemente das probabilidades de sucesso da demanda, ao menos encontra-se um corpo de julgadores que, na maioria das vezes, possui os conhecimentos técnicos necessários para solucionar a controvérsia apresentada para julgamento".

Reconhecida a falta de especialidade técnica e outras limitações naturais dos juízes, obrigados que estão a lidarem em seu dia-a-dia com matérias de toda ordem e natureza, a sentença esperada seria a escolha de um dos extremos, o que se mostra desproporcional, seja a qual das partes a decisão venha a favorecer. Para um caso como esse, ou a sentença adotará algum fundamento alinhado com o positivismo formalista ${ }^{2}$ (RIBEIRO, 2003, p. 10/11), considerando que não poderia a

\footnotetext{
${ }^{2}$ RIBEIRO, Ricardo Lodi. Justiça, Interpretação e Elisão Tributária. Rio de Janeiro: Lumen Juris, 2003. p. 10-11: “No Brasil, a concepção formalista do direito tributário encontrou receptividade ampla na doutrina...tal visão - que reduziu a interpretação da norma tributária à mera subsunção, como se o aplicador da lei fosse um autônomo e o legislador 
administração fazendária, por reserva à lei, atuar como legislador positivo ${ }^{3}$ (XAVIER, 2001. p. 107) ou, em sentido inverso, a opção do juiz será pela aplicação da norma antielisiva, considerando assim que o contribuinte teve a intenção de ocultar a realização do fato gerador de contribuição previdenciária, e que na verdade os aportes a título de previdência complementar seriam salários mascarados pelo programa de benefícios da empresa. Independente de qual seja a opção, o que nos importa aqui é a causa de uma ou outra decisão, ambas socorridas por fundamentos generalistas. Ela não será proferida por uma convicção, mas sim pelas limitações do juiz em aprofundar tecnicamente o exame da questão.

Como conclusão das pesquisas realizadas na área do comportamento institucional, Sunstein e Vermeule salientam que em comparação com os tribunais, é provável que as agências tenham bom senso de que uma saída do formalismo prejudicará seriamente um esquema regulatório; portanto, seria apropriado deferir às agências um maior grau de flexibilidade interpretativa. O nível mais elevado de especialização confere maior capacidade institucional para solucionar questões eminentemente técnicas. Ao contrário, quando tais questões são confiadas aos tribunais, as limitações técnicas obrigam os juízes a se socorrerem de fundamentos generalistas ${ }^{4}$ (SUNSTEIN; VERMEULE, 2002. p. 04).

Embora os autores se refiram às agências norte-americanas, a mesma conclusão se aplica ao CARF. De fato, no exercício da competência para solucionar divergências de teses jurídicas com formação de precedentes e possibilidade de efeitos sobre toda a administração fazendária quando sumuladas produz efeitos muito próximos à regulação em matéria tributária.

Portanto, defendemos aqui que essa bounded rationality ${ }^{5}$ (SIMON, 1972. p. 170) nas decisões confiadas aos tribunais pode ser reduzida quando as competências são alocadas de acordo com a capacidade institucional de cada um dos atores. O presente caso que analisamos não envolve

\footnotetext{
capaz de prever todos os signos de manifestação de riqueza em seus mínimos detalhes...Com isso permitiu-se que a elisão fiscal passasse a ser uma atividade utilizada em escalas que inviabilizaram um sistema tributário baseado na isonomia e na capacidade contributiva, em nome de uma falsa segurança jurídica..."

${ }^{3}$ Para essa corrente da teoria geral da interpretação, a desconfiança contra a administração fazendária é tanta que chega a afirmar ser inaplicável no direito tributário o abuso de direito. O argumento é que o agente fiscal sempre quando instado a aplicar a regra de incidência tributária com algum grau de subjetividade ou indeterminação "gelará de justo terror todos os que realizam negócios menos tributados que outros". XAVIER, Alberto. Tipicidade da Tributação, Simulação e Norma Antielisiva. São Paulo: Dialética, 2001. p. 107.

${ }^{4}$ SUNSTEIN, Cass R.; VERMEULE, Adrian. Interpretation and Institutions. John M. Olin Program in Law and Economics Working Paper, $\mathrm{n}^{\circ}$ 156, 2002, p. 4. "We also urge that even if courts should follow the ordinary meaning of text, it is reasonable to suggest that administrative agencies need not, in part because agencies are specialists rather than generalists. Compared to courts, agencies are likely to have a good sense of whether a departure from formalism will seriously damage a regulatory scheme; hence it is appropriate to allow agencies a higher degree of interpretive flexibility".
}

5 SIMON, Herbert. "Theories of Bounded Rationality". In: MCGUIRE, Charles Bartlett; RADNER, Roy Editions. Decision and Organization. New York: American Elsevier, 1972. p. 170. 
discussão sobre constitucionalidade ou o desenvolvimento de teses jurídica mais amplas e complexas; portanto, não se está aqui generalizando. A solução que se faz necessária é o desenvolvimento de um standard, possível com a experiência e especialidade técnica do órgão administrativo que corriqueiramente enfrenta casos como esses. A partir dos inúmeros casos semelhantes que são enfrentados pelas turmas de julgamento especializadas, o CARF desenvolveu uma capacidade para concluir sobre algum padrão, que no caso será a fixação de um tempo mínimo razoável para que, de um lado, não se permita a elisão fiscal abusiva e, de outro, não se penalize desproporcionalmente o contribuinte que eventualmente quis proporcionar a seus empregados um plano de benefícios apenas mais generoso, nada mais. O que não é suficiente para afastar a imunidade tributária para impor a tributação sobre todos os aportes junto às entidades abertas.

Para uma abertura nas discussões sobre esse prazo mínimo aceitável, deve-se ter em mente que previdência, seja ela a social, de natureza obrigatória, ou complementar, facultativa, ainda que oferecida por entidades abertas (instituições financeiras), é instituída tendo como referência acontecimentos futuros, muitos dos quais a longo prazo. A previdência social e a que lhe complementa não foram criadas para benefícios a serem pagos "da noite para o dia" cujo evento causal seja certo quanto a ocorrência e preciso quanto ao momento. Ao contrário, ser previdente é se antecipar a fim de minimizar as conseqüências gravosas decorrentes de um evento futuro.

Não se desconhece que a previdência complementar privada das entidades abertas é um seguro privado e como tal faz parte do sistema financeiro nacional, um produto adquirido das instituições financeiras como investimento com finalidade de capitalização de valores aportados ${ }^{6}$. Há uma autonomia do contratante em livremente estipular as cláusulas do plano de benefício e nele os prazos de resgate; contudo, essa livre iniciativa da relação jurídica privada em torno do direito à previdência complementar poderá ser abusivo quando utilizado para a substituição da remuneração dos empregados.

Por fim, para que seja apresentado ao menos um ponto de referência trazido pelo direito comparado, a experiência norte-americana do ERISA (Employee Retirement Income Security Act) na regulamentação dos planos de previdência privada na modalidade contribuição definida concluiu pela escolha de duas opções a critério do interessado: a possibilidade de resgate total após 3 anos de contribuições ou, alternativamente, resgates gradativos de $20 \%$ após 2 anos de contribuição, com $100 \%$ após 6 anos de contribuições do empregador ${ }^{7}$.

\footnotetext{
6 Banco Central do Brasil. Disponível em: https://www.bcb.gov.br/pre/composicao/composicao.asp/. Acesso em: 17/09/2017.

7 Disponível em: https://www.legalmatch.com/law-library/article/retirement-plan-vesting-schedule.html/ Acesso em: 17/09/2017: “2) Defined Contribution Plan: Employer's Matched Contributions It's worth noting that under some defined contributions plans, employees becomes immediately vested in their employers' contributions. However, in a typical defined contributions plan, there are again two possibilities - the cliff vesting and the graduated vesting: Cliff Vesting -
} 
Tratando-se de previdência complementar na modalidade de concessão pelas entidades abertas, de fato, seria um exagero a necessidade do cumprimento dos períodos de carência previstos para a previdência social ${ }^{8}$. A exigência não se aplica à previdência privada, somente à pública. $\mathrm{O}$ prazo mínimo para resgate das contribuições vertidas pelo empregador é um parâmetro objetivo delimitador da efetiva correspondência entre a substancialidade e a forma escolhida pelo contribuinte, a fronteira entre uma previdência complementar propriamente dita e uma forma para elisão fiscal abusiva caracterizada pela substituição das parcelas remuneratórias ordinárias do empregado.

Essa é uma legítima e necessária atribuição do CARF. Legítima porque é quem detém melhor capacidade institucional para as escolhas eminentemente técnicas e necessária porque sua omissão infringi a segurança jurídica do contribuinte e, consequentemente, desmotiva novas concessões de previdência complementar aos empregados, o que também frustra a finalidade da LC $\mathrm{n}^{\circ} 109 / 2001$.

Acreditamos que os prazos fixados na regulação dos planos de previdência privada pela ERISA (Employee Retirement Income Security Act) não destoam da realidade brasileira. De acordo com a finalidade de fixação de um prazo mínimo que afaste a caracterização de uma elisão fiscal abusiva pelo propósito de substituição das parcelas remuneratórias ordinárias, nas duas modalidades (Cliff vesting e Gaduated vesting), os prazos mínimos superam 1 ano. É um parâmetro importante para nossa realidade em que muitos dos direitos assegurados aos trabalhadores brasileiros são concedidos anualmente: gratificação natalina, adicional de férias, participação nos lucros ou resultados da empresa, abonos salariais etc. Um prazo superior a 1 ano para resgate das contribuições em previdência complementar confere ao contribuinte a segurança de que não seriam confundidas com esses direitos concedidos anualmente.

\section{CONCLUSÃO}

Nossa proposta aqui defendida não invade a competência do judiciário como guardião contra eventuais atos lesivos aos interesses dos contribuintes; portanto, nossa proposta de deferência

\footnotetext{
under this schedule, an employee becomes $100 \%$ vested in the employer's contributions after 3 years of work. Graduated Vesting - here again there is a schedule of gradual vesting contingent on the employee's years of work. In 2 years, an employee is at least $20 \%$ vested in employer's contributions. After 6 years, an employee becomes 100\% vested in employer's contributions".

${ }^{8}$ BRASIL. Lei no 8.213 , de 24/07/91. Diário Oficial da República Federativa do Brasil, Poder Executivo, Brasília, DF, 25/07/91: "Art. 24. Período de carência é o número mínimo de contribuições mensais indispensáveis para que o beneficiário faça jus ao beneficio, consideradas a partir do transcurso do primeiro dia dos meses de suas competências. Art. 25. A concessão das prestações pecuniárias do Regime Geral de Previdência Social depende dos seguintes periodos de carência, ressalvado o disposto no art. 26: ... II - aposentadoria por idade, aposentadoria por tempo de serviço e aposentadoria especial: 180 contribuições mensais".
} 
a administração fazendária de exercer plenamente sua capacidade institucional em nada esbarra a inafastabilidade do controle jurisdicional previsto do artigo $5^{\circ}$, inciso XXXV de nossa Constituição.

O que não se pode ignorar é que muitas questões na seara do direito tributário têm natureza muito mais técnica, e em muitos casos são solucionadas com conhecimentos específicos estudados em outras áreas, e não com as teorias mais abrangentes do direito. De fato, o direito tributário dialoga com economia, administração, contabilidade, dentre outras áreas de conhecimento. Devemos ter a humildade em reconhecer que em muitos casos a solução não está nas teorias gerais do direito, mas na pertinência ou não do ato praticado com as técnicas e instrumentos de gestão e a correspondência dos registros contábeis com os efeitos econômicos.

O caso que escolhemos como objeto dessa análise muito bem evidencia o que defendemos. Quando a físcalização se convence que um programa de previdência complementar adota uma característica que destoa da normalidade e transparece um propósito de utilização abusiva para redução do tributo, estamos diante de um impasse por ausência de um parâmetro objeto seguro que delimite, de uma lado, o regular exercício de um direito amparado pela imunidade tributária e, de outro, a substituição das parcelas remuneratórias ordinárias pela concessão de um benefício com finalidade predominantemente de redução da contribuição previdenciária.

A melhor escolha, seguramente, não está nos extremos: em uma ponta, a plena liberdade de fixação de qualquer prazo para resgate das contribuições do empregador em benefício dos empregados (de 1 dias a décadas de participação no programa) e, na outra, o afastamento da imunidade por entender que o direito ao resgate somente nasce da aposentadoria do empregado.

Uma vez submetida a questão a apreciação do juiz, inevitavelmente, a decisão recairá sobre um dos extremos, apoiada em fundamentos generalistas. Ela não será proferida por uma convicção, mas sim pelas limitações em aprofundar tecnicamente o exame da questão e pela falta de experiência em casos paradigmáticos ou semelhantes. Aqui residem as características que conferem ao CARF maior capacidade institucional para a fixação de um standard mais razoável e preciso que ofereça uma solução confiável e segura ao contribuinte. Em seu dia-a-dia, as dezenas de casos submetidos à apreciação dos julgadores administrativos consolidam ao longo do tempo um padrão. A experiência adquirida na construção de uma "jurisprudência administrativa" favorece a constatação de parâmetros para a delimitação das condutas não alcançadas pela regra de incidência ou, como no presente caso, em conformidade com a regra de isenção ou imunidade.

O reconhecimento dessa deferência ao órgão administrativo traz benefícios para todos: para o contribuinte, pela segurança jurídica e razoabilidade da decisão; para a administração fazendária, pela redução da litigiosidade e eficiência; e para o judiciário, a possibilidade de se dedicar às questões jurídicas mais gerais, como as teses sobre inconstitucionalidades e ilegalidades. 


\section{REFERÊNCIAS}

RIBEIRO, Ricardo Lodi. Justiça, Interpretação e Elisão Tributária. Rio de Janeiro: Lumen Juris, 2003.

ROCHA, Sergio André. Da Lei à Decisão: a Segurança Jurídica Tributária Possível na Pósmodernidade. Rio de Janeiro: Lumen Juris, 2017.

SIMON, Herbert. "Theories of Bounded Rationality". In: MCGUIRE, Charles Bartlett; RADNER, Roy Editions. Decision and Organization. New York: American Elsevier, 1972.

SUNSTEIN, Cass R.; VERMEULE, Adrian. Interpretation and Institutions. John M. Olin Program in Law and Economics Working Paper, nº 156, 2002.

VERMEULE, Adrian. Mechanisms of Democracy: Institutional Design Writ Small. Oxford: Oxford University Press, 2007.

XAVIER, Alberto. Tipicidade da Tributação, Simulação e Norma Antielisiva. São Paulo: Dialética, 2001. 